\title{
The oncolytic herpes simplex virus vector, G47 $\Delta$, effectively targets tamoxifen-resistant breast cancer cells
}

\author{
JINGJING FAN*, HUA JIANG*, LIN CHENG and RENBIN LIU \\ Breast Cancer Center, The Third Affiliated Hospital of Sun Yat-Sen University, Guangzhou 510630, P.R. China
}

Received October 14, 2015; Accepted November 18, 2015

DOI: $10.3892 /$ or.2015.4539

\begin{abstract}
The aim of the present study was to establish a tamoxifen-resistant cell line (MCF-7/TAM-R) and to investigate the therapeutic effect of G47D on this cell line both in vitro and in vivo. In the present study, the MCF-7/TAM-R monoclonal subline was established after exposing MCF-7 cells to tamoxifen for 21 days. Then, it was compared with a wildtype MCF-7 subline (MCF-7W), which was not treated with tamoxifen. Cell proliferation, viability, cell cycle and apoptosis analyses were carried out to examine the characteristics of the MCF-7/TAM-R cells. Both in vitro and in vivo toxicity studies were conducted to investigate the therapeutic effect of G47 $\Delta$ on the MCF-7/TAM-R cells. Compared to the MCF-7W cells, we found that the MCF-7/TAM-R cells exhibited a higher proliferation ability $(\mathrm{P}<0.05)$ and a stronger resistance to the cytotoxic effects induced by 4-hydroxytamoxifen (4-OHT) $(\mathrm{P}<0.05)$. G47 demonstrated a high cytotoxic effect on both the MCF-7/TAM-R and MCF-7W cell lines. After being infected with G47 $\Delta$ at an MOI of $0.01,>90 \%$ of the MCF-7/ TAM-R and MCF-7W cells died on day 5. G47 $\Delta$ induced cell cycle arrest in the G2/M phase. Furthermore, G47 $\Delta$ inhibited tumor growth in subcutaneous tumor models of both MCF-7/ TAM-R and MCF-7W. Thus, we conclude that G47D, a third generation oncolytic herpes simplex virus, is highly sensitive and safe in targeting tamoxifen-resistant breast cancer cells both in vitro and in vivo.
\end{abstract}

\section{Introduction}

Breast cancer is the most common malignant neoplasm in women, and more than 1.6 million newly diagnosed cases

Correspondence to: Professor Renbin Liu, Breast Cancer Center, The Third Affiliated Hospital of Sun Yat-Sen University, 600 Tianhe Road, Guangzhou 510630, P.R. China

E-mail: liur@vip.163.com

*Contributed equally

Key words: breast cancer, oncolytic herpes simplex virus, cytotoxicity, tamoxifen resistance were reported in 2012 worldwide (1). The National Cancer Institute has reported that over $70 \%$ of breast cancers express the estrogen receptor (ER) (2), providing biological evidence to administer endocrine therapy as referenced management for patients with ER-positive diseases. This strategy has been widely used in breast cancer prevention and treatment (3-8). Unfortunately, recent studies have revealed that $\sim 50 \%$ of cases of ER-positive breast cancer (9) do not respond or partially respond to hormonal therapy due to either intrinsic or acquired therapeutic resistance. Among all antiestrogenic compounds, tamoxifen, which blocks ER signaling by binding to the corresponding receptor, is the most frequently used medication in the past decades $(7,10,11)$. However, nearly one-third of ER-positive breast cancer patients are not sensitive to tamoxifen (12). In such cases, aromatase inhibitors (AIs) alone or in combination with ovarian suppression are used to treat breast cancer. Nonetheless, AIs and ovarian suppression are associated with several adverse events, which severely hamper the quality of life of such patients. Ovarian ablation (surgical or radiation) completely blocks the source of ovarian estrogen, leading to an irreversible menopause at a young age. Moreover, bone density loss (13) and cardiovascular events $(8,14)$ usually occur in patients treated with AIs or ovarian suppression. At present, only few therapeutic strategies with significant side-effects are available for tamoxifen-resistant patients. Therefore, safer and more effective treatments for these patients are urgently needed.

Oncolytic herpes simplex virus (oHSV) is a promising agent for various types of cancers. It has been widely used in cancer research studies (15). Furthermore, several oncolytic viruses have been tested in clinical trials, such as NV1020, G207, HF10 and OncoVEX (GM-CSF). These viruses can safely and effectively target cancer cells (16-18). G47D is a third generation vector; it is generated from G207 by deleting the non-essential $\alpha-47$ gene. A previous study reported that, compared to $\mathrm{G} 207, \mathrm{G} 47 \Delta$ replicates and spreads better in infected cells. Furthermore, G47 $\Delta$ was found to be more efficient in inhibiting the growth of tumors (19). G47 $\Delta$ has also been employed in a phase I clinical trial of progressive glioblastoma (20).

In the present study, we established the MCF-7 tamoxifen-resistant monoclonal subline and the MCF-7 wild-type monoclonal subline (21), and investigated the cytotoxic effects of the G47D oHSV vector on the tamoxifen-resistant cell line in vitro and in vivo. 


\section{Materials and methods}

Cell culture and virus. MCF-7 and Vero cells were provided by $\mathrm{Dr} \mathrm{Mu}$ Sheng Zeng (Sun Yat-Sen University Cancer Center, Guangzhou, China). We cultured both types of cells in Dulbecco's modified Eagle's medium (DMEM; Gibco, Shanghai, China), which was supplemented with glucose $(4.5 \mathrm{~g} / \mathrm{l})$ and $10 \%$ fetal bovine serum (FBS; Gibco, Grand Island, NY, USA) at $37^{\circ} \mathrm{C}$ in an atmosphere containing $5 \% \mathrm{CO}_{2}$.

Oncolytic HSV G47D was purchased from MediGene Inc. (San Diego, CA, USA), and it was reproduced in Vero cells. After achieving approximately $80 \%$ confluency, the Vero cells were infected with $\mathrm{G} 47 \Delta$ at a multiplicity of infection (MOI) of 0.03 and incubated at $37^{\circ} \mathrm{C}$ in $5 \% \mathrm{CO}_{2}$. All infected cells were harvested and centrifuged at 1,000 $\mathrm{x}$ g for $6 \mathrm{~min}$, and then the liquid supernatant was discarded and $1 \mathrm{ml}$ virus buffer $(150 \mathrm{mM} \mathrm{NaCl} / 20 \mathrm{mM}$ Tris, $\mathrm{pH} 7.5)$ was added to the system. Thereafter, we subjected the cells to three freeze-thaw cycles; the resultant liquid supernatant was stored at $-80^{\circ} \mathrm{C}$ for future analyses.

Virus titers were determined by plaque assays on the Vero cells. In brief, the Vero cells were seeded into 6-well plates with DMEM and $10 \% \mathrm{FBS}$ at $37^{\circ} \mathrm{C}$ in $5 \% \mathrm{CO}_{2}$ and infected with $700 \mu$ virus dilute $\left(10^{-4} / \mathrm{ml}, 10^{-6} / \mathrm{ml}, 10^{-8} / \mathrm{ml}\right.$ or $\left.10^{-10} / \mathrm{ml}\right)$ when cells achieved $100 \%$ confluency. The infected cells were cultured at $37^{\circ} \mathrm{C}$ in $5 \% \mathrm{CO}_{2}$ for $48 \mathrm{~h}$ before subsequent $\mathrm{X}$-gal staining for plaque counting. The following equation was applied to calculate virus titers: Virus titers $=$ plaque numbers/0.7 x dilution ratio (19).

Establishment of the tamoxifen-resistant cell line. We derived MCF-7/tamoxifen-resistant (MCF-7/TAM-R) and wildtype MCF-7 (MCF-7W) cells from the tamoxifen-sensitive MCF-7 cell line (21). To establish the MCF-7/TAM-R monoclonal subline, MCF-7 cells were seeded in a 10- $\mathrm{cm}$ dish at a density of $1.0 \times 10^{7}$ cells/dish. The cells were cultured in DMEM (5\% FBS) containing $1 \mu \mathrm{M}$ of 4-hydroxytamoxifen (4-OHT); this culture was maintained for 21 days at $37^{\circ} \mathrm{C}$ in $5 \% \mathrm{CO}_{2}$. Then, the survived monoclonal cells were cultured in complete medium without tamoxifen for 7 days. After that, each MCF-7/TAM-R monoclonal was separately picked and cultured in a 96-well plate. In order to maintain tamoxifen resistance in the MCF-7/TAM-R cells, we cultured them in a complete medium containing $0.1 \mu \mathrm{M}$ of 4-OHT. To obtain the MCF-7W monoclonal subline, MCF-7 cells were seeded in a $10-\mathrm{cm}$ dish at a density of $<100$ cells/dish and cultured without 4-OHT for 30 days. Then, we selected the MCF-7W monoclone and incubated the cells in a 96-well plate.

Cell proliferation assays. MCF-7/TAM-R and MCF-7W cells were separately seeded into a 96 -well plate at a density of $5.0 \times 10^{3}$ cells/well and cultured in DMEM (5\% FBS) at $37^{\circ} \mathrm{C}$ in $5 \% \mathrm{CO}_{2}$. Cell proliferation was measured by Cell Counting Kit-8 assay (CCK-8; Dojindo, Japan) for 5 days. All experiments were triplicated.

Cell viability assays. MCF-7/TAM-R and MCF-7W cells were separately seeded overnight in a 96-well plate at a density of $5.0 \times 10^{3}$ cells/well. The cells were then treated with 4-OHT or vehicle (ethanol, control). In the treatment group, the doses of tamoxifen were exponentially increased $\left(10^{-8}, 10^{-7}, 10^{-6}\right.$, $10^{-5}$ and $\left.10^{-4} \mathrm{~mol} / \mathrm{l}\right)$. After $48 \mathrm{~h}$, cell viability was evaluated using the CCK- 8 assay. Prior to this measurement, we added $100 \mu 1$ DMEM, which contained $10 \mu \mathrm{l}$ CCK-8, to each well and incubated them for $120 \mathrm{~min}$ at $37^{\circ} \mathrm{C}$. Subsequently, we measured the absorption at $450 \mathrm{~nm}$ using an enzyme standard instrument (BioTek, Winooski, VT, USA). $\mathrm{ED}_{50}$ was calculated using CompuSyn software (CompuSyn Inc., New York, NY, USA). Cell survival rate and resistance-index were computed using the following formulas:

Cell survival rate $=[$ (Average number of cells from virus-treated group)/(Average number of cells from control group)] x 100\%

Resistance-index $=\left(\mathrm{MCF}-7 / \mathrm{TAM}-\mathrm{R}_{\mathrm{ED} 50}\right) /\left(\mathrm{MCF}-7 \mathrm{~W}_{\mathrm{ED} 50}\right)$

All of the experiments were performed in triplicate.

Cell cycle analyses. MCF-7/TAM-R and MCF-7W cells were seeded separately in 6 -well plates $\left(5.0 \times 10^{5}\right.$ cells/well). Forty-eight hours after the intervention, we collected the virustreated (MOI, 0.01), 4-OHT-treated $(1 \mu \mathrm{mol} / \mathrm{l})$ and control group, individually. Then, each group of cells was washed with phosphate-buffered saline (PBS) and centrifuged at $1,000 \mathrm{x} \mathrm{g}$ for $5 \mathrm{~min}$. The sediments were resuspended into PBS at a concentration of $1.0 \times 10^{6}$ cells $/ \mathrm{ml}$. Finally, they were fixed overnight in $70 \%$ ethyl alcohol at $4^{\circ} \mathrm{C}$. A cell cycle detection kit (KeyGen, Nanjing, China) was used to analyze the phase distribution of the cell cycle. In brief, the samples were first centrifuged and resuspended in $0.1 \mathrm{ml}$ of RNase A (KeyGen). After incubating the cells at $37^{\circ} \mathrm{C}$ for $30 \mathrm{~min}$, we introduced $0.5 \mathrm{ml}$ of propidium iodide (PI; KeyGen) staining solution to the system. The distribution of the cell cycle was evaluated by flow cytometry (BD LSR II; BD Biosciences, Franklin Lakes, NJ, USA).

Analysis of cell apoptosis. MCF-7/TAM-R and MCF-7W cells were separately seeded in a 6 -well plate $\left(5.0 \times 10^{5}\right.$ cells/well $)$ and harvested after $48 \mathrm{~h}$. Each group of cells was washed twice with PBS. Then, 5.0x $10^{5}$ cells of each group were suspended in $500 \mu \mathrm{l}$ binding buffer. Then, the cells were stained with Annexin V and PI [Annexin V-FITC apoptosis detection kit (KeyGen)] according to the manufacturer's instructions. All the data were analyzed using FlowJo software (Tree Star, Inc., Ashland, OR, USA).

Western blot analyses. MCF-7/TAM-R and MCF-7W cells were placed into 6-well plates. Then, the cells were treated with 4-OHT or vehicle (ethanol) for $48 \mathrm{~h}$. After the intervention, the cells were washed twice with ice-cold PBS and lysed with a whole cell lysis kit (KeyGen). The protein density was measured using the BCA protein quantification kit (KeyGen). Then, all the samples were stored at $-20^{\circ} \mathrm{C}$ before being subjected to electrophoresis. Briefly, the electrophoresis was carried out by separating $50 \mu \mathrm{g}$ of total cellular protein on $10 \%$ or $15 \%$ SDS-polyacrylamide gel. Then, the cellular protein was electrotransferred onto a $0.22-\mu \mathrm{m}$ thick nitrocellulose membrane (Millipore, Billerica, MA, USA). Thereafter, the membrane was blocked in 5\% bovine serum albumin (Roche, Basel, Switzerland) in TBS-Tween buffer (TBS-T) for $1 \mathrm{~h}$ and 

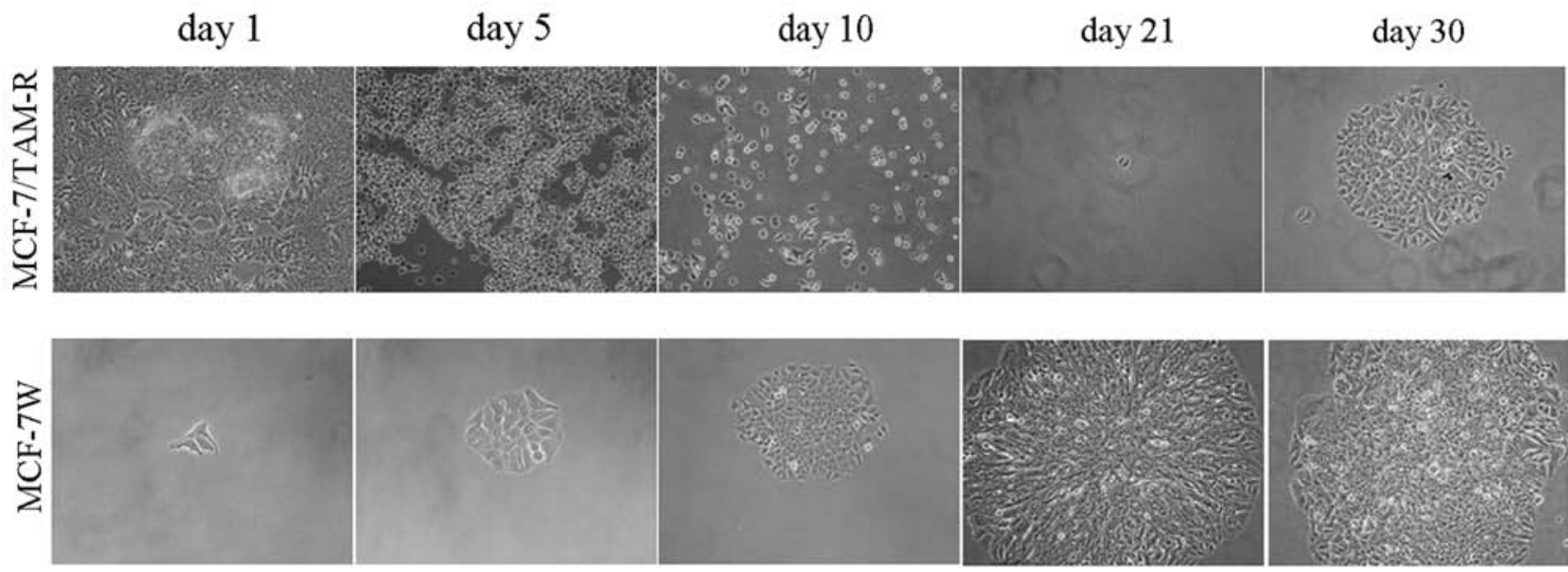

Figure 1. Establishment of MCF-7/TAM-R and MCF-7W monoclonal sublines. At a density of 1.0x10 7 cells/dish, MCF-7 cells were seeded in a 10-cm dish. Then, they were cultured for 21 days in DMEM (5\% FBS), containing $1 \mu \mathrm{M}$ of 4-OHT. Thereafter, the cells were suspended in DMEM (5\% FBS) without drugs for another seven days. MCF-7 cells were seeded in a 10-cm dish at a density of $<100$ cells/dish and cultured in DMEM (5\% FBS) for 30 days.

submitted to the primary and secondary antibodies. Briefly, the membrane was incubated overnight with the primary antibodies at $4^{\circ} \mathrm{C}$. After washing the membrane thrice in TBS-T, it was incubated in the secondary antibody for $1 \mathrm{~h}$ at room temperature. The immunoreactive protein bands were detected using a chemiluminescence imaging system (Tanon-5200; Tanon, Guangzhou, China). The following antibodies were used: ER- $\alpha$ receptor (1:1,000 diluted), ER- $\beta$ receptor $(1: 1,000$ diluted) (both from Abcam, Cambridge, UK), Bcl-2-interacting killer (BIK; 1:1,000 diluted), caspase-7 (1:1,000 diluted) and $\beta$-actin (1:3,000 diluted) (all from Cell Signaling Technology, Boston, MA, USA). The secondary antibody was HRP-goat anti-rabbit IgG (1:2,000 diluted; Invitrogen, Shanghai, China).

In vitro cytotoxicity. MCF-7W and MCF-7/TAM-R cells were either infected with G47 $\Delta$ at different MOIs (MOI, 0.01, 0.1 or 1) or mock infected and incubated in DMEM (1\% FBS) at $37^{\circ} \mathrm{C}$ in $5 \% \mathrm{CO}_{2}$. After infection, the cells were stained with $\mathrm{X}$-gal solution (Beyotime, Shanghai, China) and counted on a hemocytometer (Qiujing, Shanghai, China) for 5 days. The average number of cells from duplicate wells was recorded as the percentage of mock-infected cells.

In vivo experiment. All the protocols for the animal experiments were approved by the Ethics and Use Committee of the Research Institute at Sun Yat-Sen University, Guangdong, China. Female BALB/c nude mice (4 weeks of age, 14-16 g in weight) were purchased from Vital Rival Laboratories (Beijing, China). The mice were randomly divided into the following four groups (5 mice/group): MCF-7/TAM-R control group, MCF-7/TAM-R virus-treated group, MCF-7W control group, and MCF-7W virus-treated group. MCF-7/TAM-R and MCF-7W cells $\left(1.0 \times 10^{7}\right)$ were suspended in $100 \mu \mathrm{l}$ of DMEM containing 25\% Matrigel (Corning, USA) and separately injected subcutaneously into the groin of each mouse. When the tumor attained a maximum diameter of $5 \mathrm{~mm}$, we injected $50 \mu \mathrm{l}$ of $\mathrm{G} 47 \Delta\left(2.0 \times 10^{7} \mathrm{pfu}\right.$, repeated 4 times at an interval of 3 days) in the two virus-treated groups; the same volume of virus buffer (150 mM NaCl, $20 \mathrm{mM}$ Tris, $\mathrm{pH} 7.5$ ) was injected into the two control groups. The tumor size was evaluated using a Vernier caliper every 3 days, and the tumor volume $=\left(\right.$ width $^{2} \mathrm{x}$ length $) / 2$. On day 7 after injecting the virus, a mouse from each group was sacrificed to obtain subcutaneous tumors. Then, X-gal stain was applied to the frozen tumor sections to determine the efficacy of infection in each group (tissue showing blue staining was considered to be infected with G47 $\Delta$ ). The remaining animals were sacrificed on day 60 , and their tumors were resected and fixed in $4 \%$ paraformaldehyde (Beijing Leagene Biotech Co., Beijing, China). The date of death was recorded for further survival analyses. H\&E staining and immunohistochemical staining (Histostain-Plus kit; ZSGB-BIO, Beijing, China) were carried out to determine the tumor characteristics and to analyze the expression of ER- $\alpha$ and ER- $\beta$. For ER- $\alpha$ and ER- $\beta$ analyses, five fields were randomly selected from each sample and examined under a microscope (magnification, x100).

Statistical analyses. The statistical analyses were carried out using SPSS 22.0 (IBM, Armonk, NY, USA). The reported values were presented as mean \pm standard deviation (SD). The difference between the groups was evaluated using pairedsample t-test and one-way ANOVA. A P-value of $<0.05$ was considered to indicate a statistically significant result.

\section{Results}

Characteristics of the MCF/TAM-R and MCF-7W cells. As shown in Fig. 1, we successfully established MCF-7/TAM-R and MCF-7W cells. The cell proliferation analyses showed that compared to the MCF-7W cell line, the MCF-7/TAM-R cell line had a higher proliferation rate $(\mathrm{P}=0.018$; Fig. 2A). Tamoxifen toxicity experiments confirmed that the $\mathrm{ED}_{50}$ of 4-OHT in the MCF-7W cells was $2.40 \pm 0.08 \times 10^{-6} \mathrm{~mol} / 1$, while the $\mathrm{ED}_{50}$ of $4-\mathrm{OHT}$ in the MCF-7/TAM-R cells was $2.98 \pm 0.51 \times 10^{-5} \mathrm{~mol} / 1(\mathrm{P}=0.007$; Fig. $2 \mathrm{~B})$. The resistance-index was $12.41 \pm 1.76$.

After $48 \mathrm{~h}$ of treatment, 4-OHT $(1 \mu \mathrm{M})$ increased cell cycle arrest in the $\mathrm{G} 0 / \mathrm{G} 1$ phase $(\mathrm{P}=0.002)$ of the MCF-7W cells (Fig. 2D); however, 4-OHT did not show a significant impact on the MCF-7/TAM-R cell cycle (Fig. 2C). 

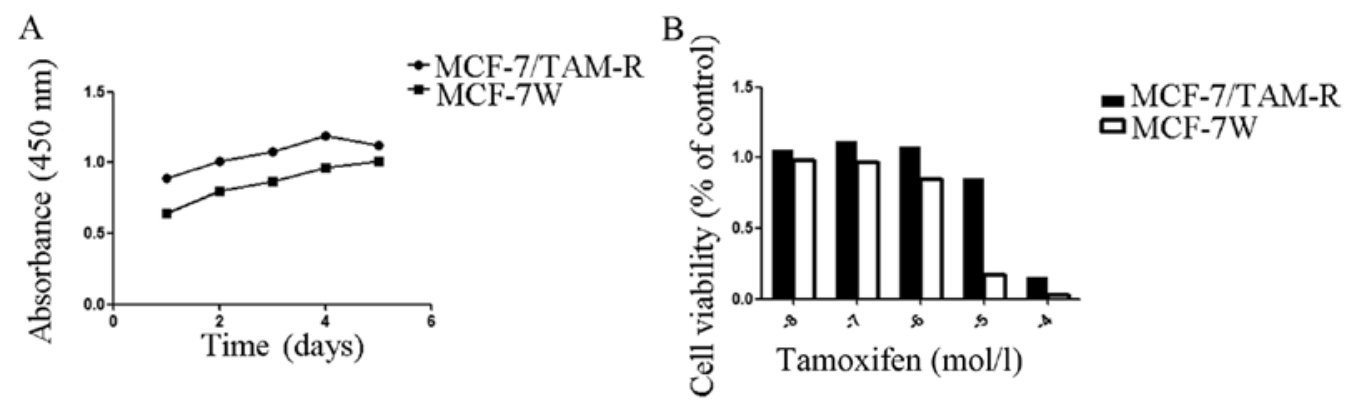

C Cell cycle distribution of MCF-7/TAM-R

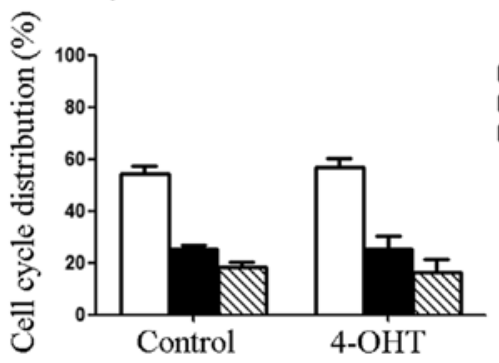

D Cell cycle distribution of MCF-7W

E
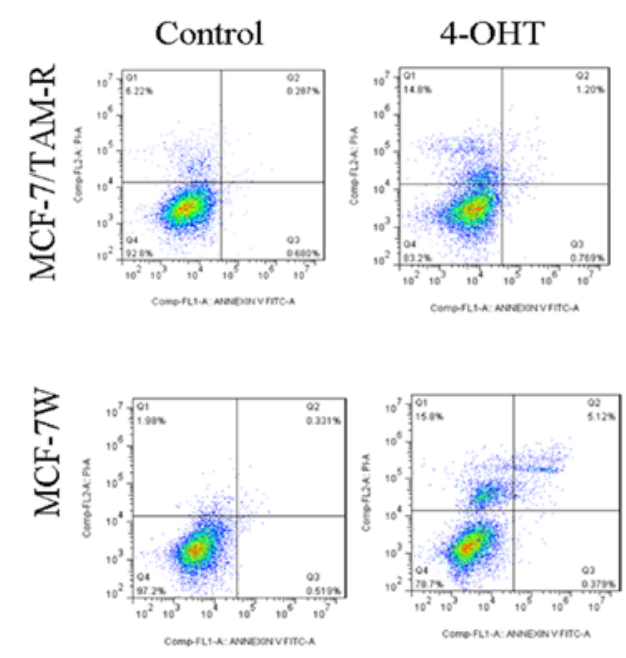

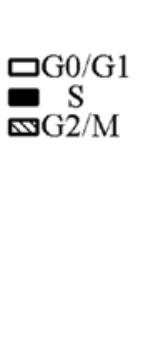

F

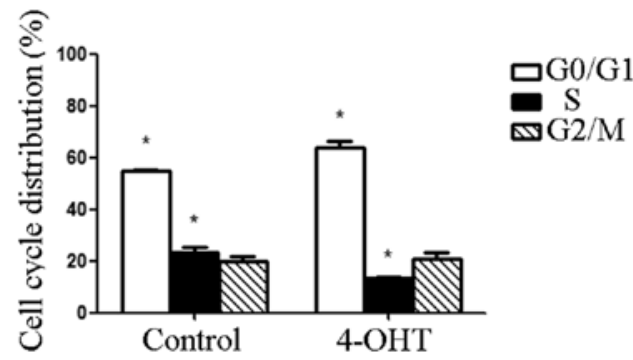

MCF-7W MCF-7/TAM-R

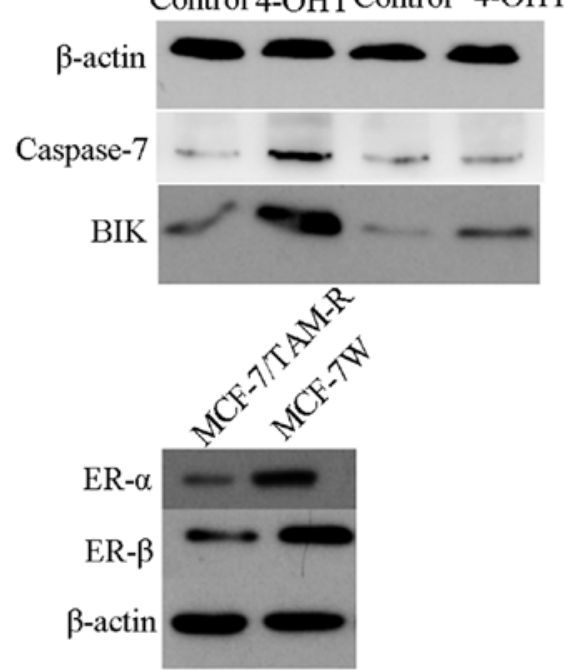

Figure 2. Identification of the tamoxifen-resistant characteristics of the MCF-7/TAM-R cells. (A) Cell proliferation experiments indicated that the MCF-7/ TAM-R cell line had a higher proliferation rate than the MCF-7W cell line $(\mathrm{P}=0.018)$. (B) Tamoxifen cytotoxic tests showed that the $\mathrm{ED}_{50}$ of $4-\mathrm{OHT}_{\mathrm{T}}$ in the MCF-7W cells was lower than that in the MCF-7/TAM-R cells ( $\mathrm{P}=0.007)$. (C-E) Cell cycle analyses and apoptosis assays confirmed the occurrence of 4-OHT-induced cell cycle arrest and apoptosis in the MCF-7W cells but not in the MCF-7/TAM-R cells. (F) Tamoxifen increased the expression of caspase-7 and BIK in the MCF-7W cells but not in the MCF-7/TAM-R cells. (G) The expression of ER- $\alpha$ and ER- $\beta$ was significantly higher in the MCF-7/TAM-R cells.

Annexin V-FITC/PI staining indicated that 4-OHT induced apoptosis in the MCF-7W cells (mock vs. 4-OHT, $0.74 \pm 0.89$ vs. $5.89 \pm 0.88 \%$; $\mathrm{P}=0.001)$. However, no significant difference was detected between the 4-OHT-treated MCF-7/TAM-R and the mock control cells $(0.94 \pm 0.19$ vs. $0.64 \pm 0.94 \% ; \mathrm{P}=0.71)$ (Fig. 2E).

Caspase-7 and BIK were assessed to determine whether 4-OHT induced the expression of apoptotic proteins in the MCF-7W and MCF-7/TAM-R cells. Western blot analyses showed that tamoxifen increased the expression of caspase-7 and BIK in the MCF-7W cell line; however, no significant difference was detected in the MCF-7/TAM-R cell line (Fig. 2F). This indicates that the MCF-7/TAM-R cells showed significant drug resistance to 4-OHT. According to western blot analyses, the expression of ER- $\alpha$ and ER- $\beta$ in the
MCF-7/TAM-R cells was significantly lower than that in the MCF-7W cells (Fig. 2F).

G47A effectively targets MCF-7/TAM-R and MCF-7W cells. To determine the susceptibility of the tamoxifen-resistant MCF-7 cell line to G47D, MCF-7/TAM-R and MCF-7W cells were cultured in 6-well plates separately, and infected with $\mathrm{G} 47 \Delta$ at $\mathrm{MOI}=0.01,0.1$ and $1 . \mathrm{G} 47 \Delta$ exhibited a similar cytotoxic effect on the MCF-7/TAM-R and MCF-7W cell lines (Fig. 3A and B). At MOI=0.01, 91\% of the MCF-7/ TAM-R and $85 \%$ of the MCF-7W cells were killed on day 5 . At $\mathrm{MOI}=0.1,91 \%$ of the MCF-7/TAM-R and $80 \%$ of the MCF-7W cells were killed on day 4 . At MOI=1, $90 \%$ of the MCF-7/TAM-R and $87 \%$ of the MCF-7W cells were killed on day 3 (Fig. 3C and D). 
A

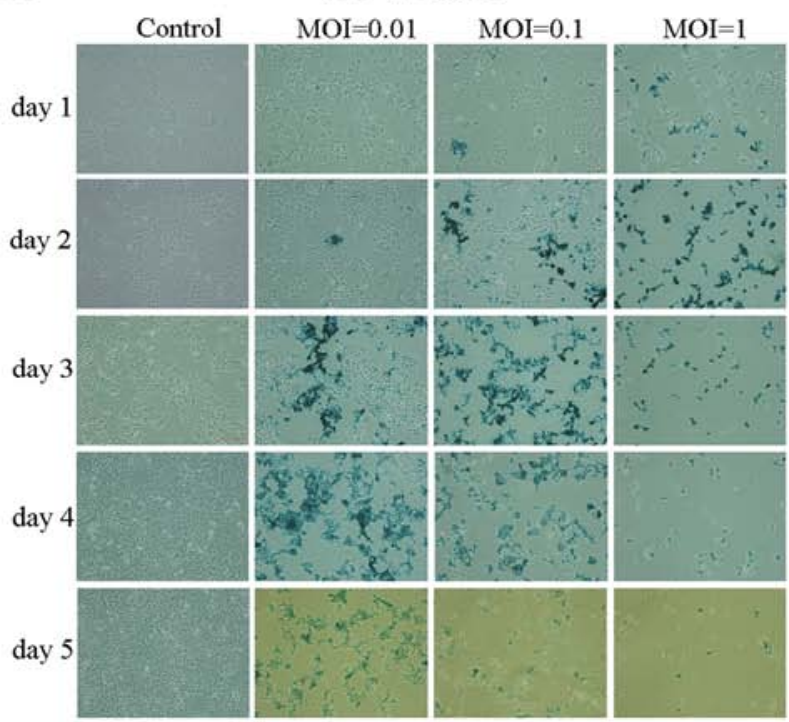

C

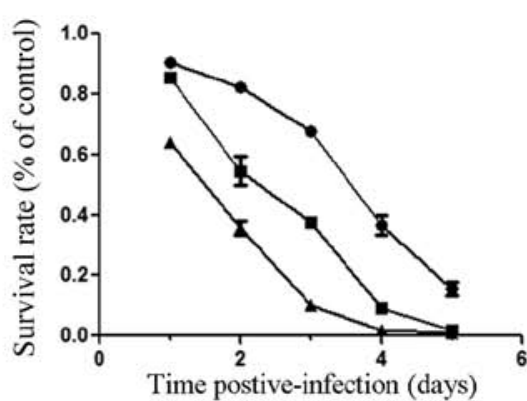

- $\mathrm{MOI}=0.01$

$\rightarrow \mathrm{MOI}=0.1$

$\leftarrow \mathrm{MOI}=1$
B

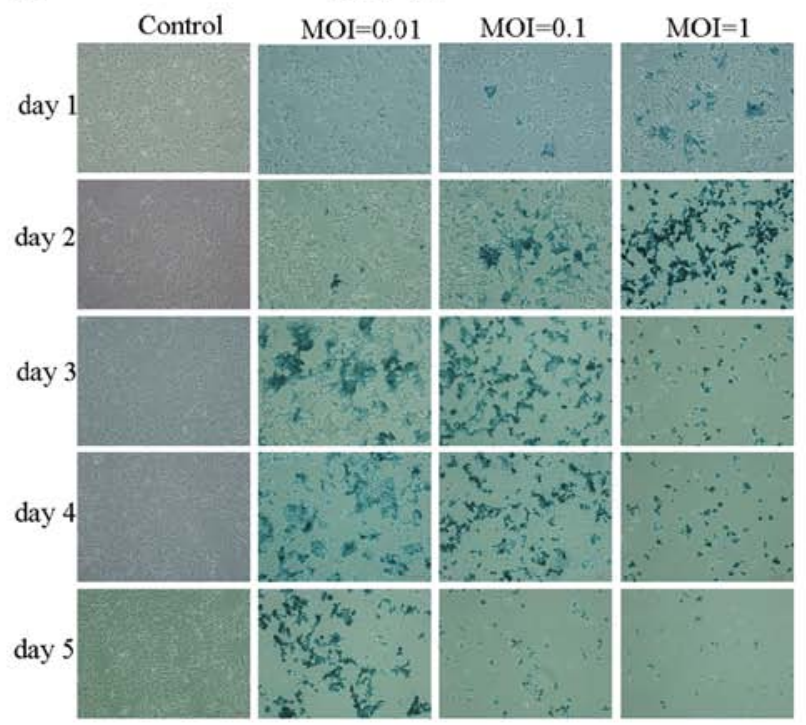

D

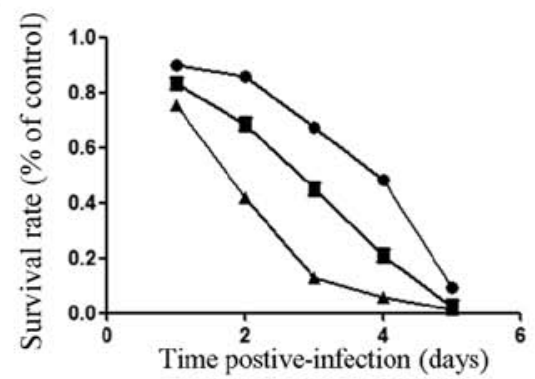

Figure 3. Cytotoxicity of G47D in the MCF-7/TAM-R and MCF-7W cell lines. (A and B) X-gal staining of the MCF-7/TAM-R and MCF-7W cells (both magnification, $x 100$ ), which were infected with G47A. (C and D) Cell survival rate of the MCF-7/TAM-R and MCF-7W cells.

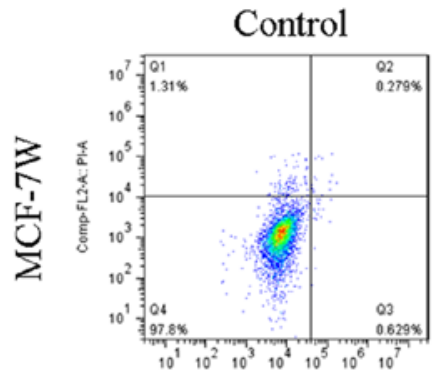

COMPDFL1-A-ANNEXINVFITCA

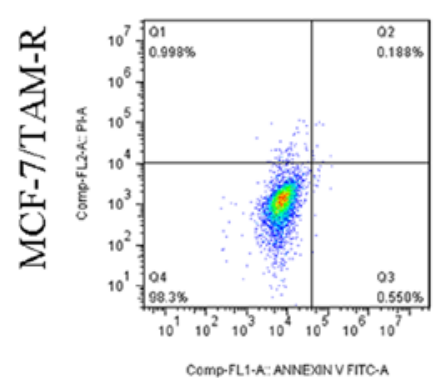

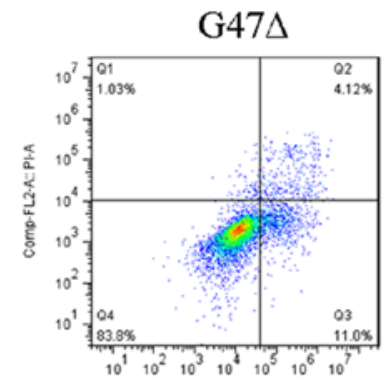

COmP-FLLA:A:Annexin VFTCA

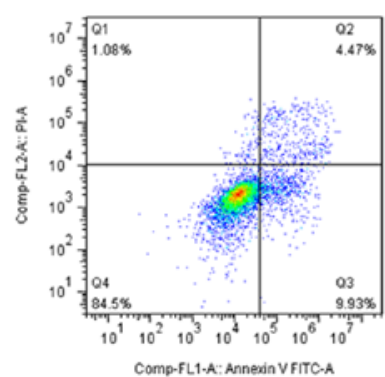

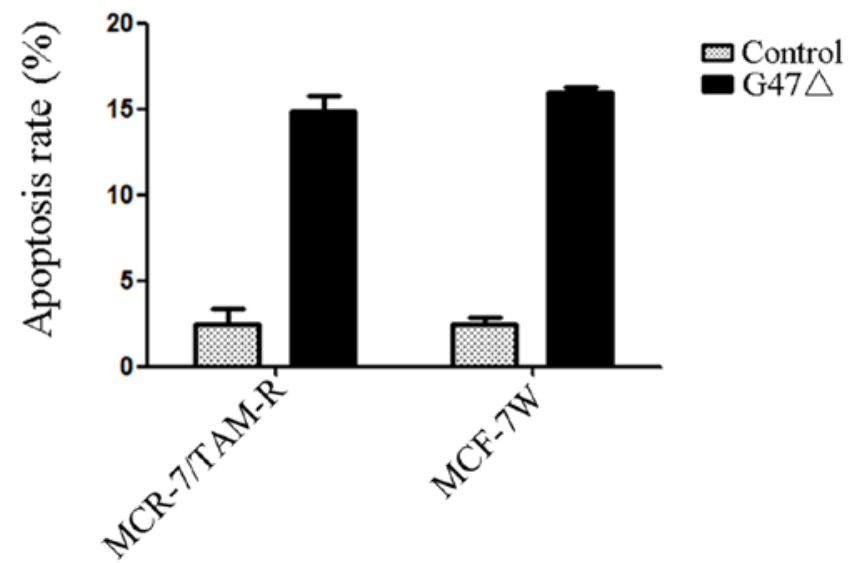

Figure 4. Apoptosis of G47D-treated MCF-7/TAM-R and MCF-7W cells. G47 significantly increased the apoptosis of the MCF-7/TAM-R (P=0.005) and MCF-7W cells $(\mathrm{P}=0.001)$.

G474 induces cell cycle arrest and increases the levels of apoptosis. G47 significantly increased cell apoptosis in the MCF-7/TAM-R cells (control vs. virus: $2.43 \pm 0.97$ vs. $14.88 \pm 0.85 \% ; \mathrm{P}=0.005$ ) (Fig. 4) and in the MCF-7W cells 

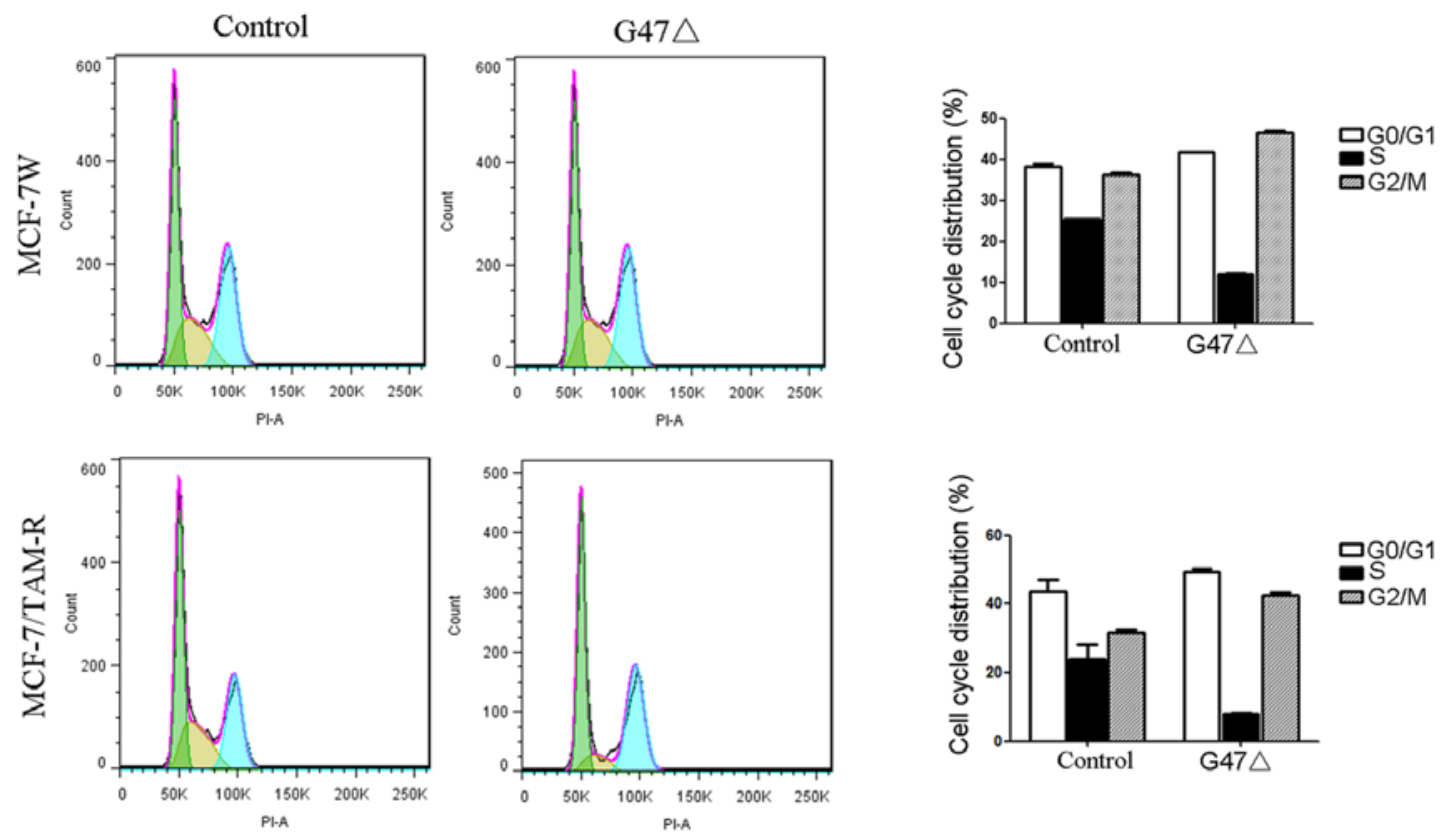

Figure 5. Cell cycle analysis of G47 $\Delta$-treated MCF-7/TAM-R and MCF-7W cells. The virus infection induced cell cycle arrest at the G2/M phase in the MCF-7/ TAM-R and MCF-7W cells $(\mathrm{P}=0.006$ and $\mathrm{P}=0.004)$.

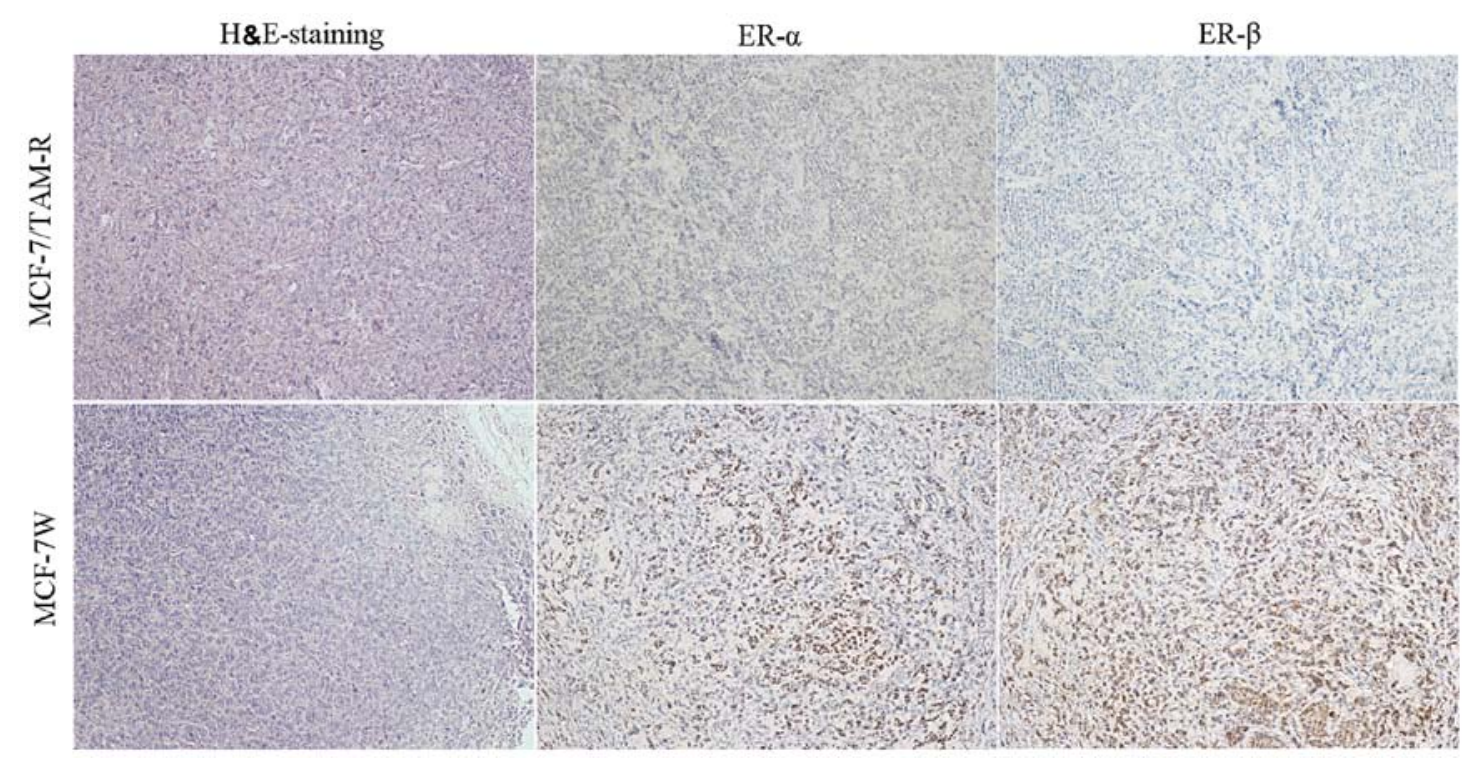

Figure 6. In vivo experiments. H\&E staining (magnification, x100) and immunohistochemical staining (magnification, x100).

(mock vs. virus: $2.49 \pm 0.40$ vs. $15.99 \pm 0.22 \%$; $\mathrm{P}=0.001$ ) (Fig. 4 ). At a definite dose $(\mathrm{MOI}=0.01), \mathrm{G} 47 \Delta$ also significantly impacted the cell cycle in both the MCF-7W and MCF-7/ TAM-R cells. Virus infection induced cell cycle arrest at the G2/M phase in both cell lines (MCF-7/TAM-R and MCF-7W; $\mathrm{P}=0.006$ and $\mathrm{P}=0.004$ ) (Fig. 5).

Antitumor efficacy of G474 in vivo. We successfully established subcutaneous tumor models of MCF-7/TAM-R and MCF-7W cells in 4-week-old female BALB/c nude mice. G47 $\Delta$ significantly inhibited tumor growth in both models (for MCF-7/TAM-R: virus vs. control, $23.83 \pm 19.64$ vs. 163.81 \pm 35.97 $\mathrm{mm}^{3}$; $\mathrm{P}=0.002$; for MCF-7W: virus vs. control, $12.63 \pm 9.15$ vs. $\left.127.33 \pm 23.64 \mathrm{~mm}^{3} ; \mathrm{P}=0.006\right) . \mathrm{G} 47 \Delta$ was able to replicate in the MCF-7/TAM-R and MCF-7W models (Fig. 7). During the observation period, no mouse mortality was noted in both the control and virus-treated groups. Immunohistochemical staining revealed that the expression of ER- $\alpha$ and ER- $\beta$ in MCF-7/TAM-R tumors was significantly lower than that in the MCF-7W tumors (Fig. 6).

\section{Discussion}

In the present study, we established MCF-7/TAM-R and MCF-7W monoclonal sublines to investigate the cytotoxic effect of G47 , a third generation oHSV, on tamoxifen-resistant 

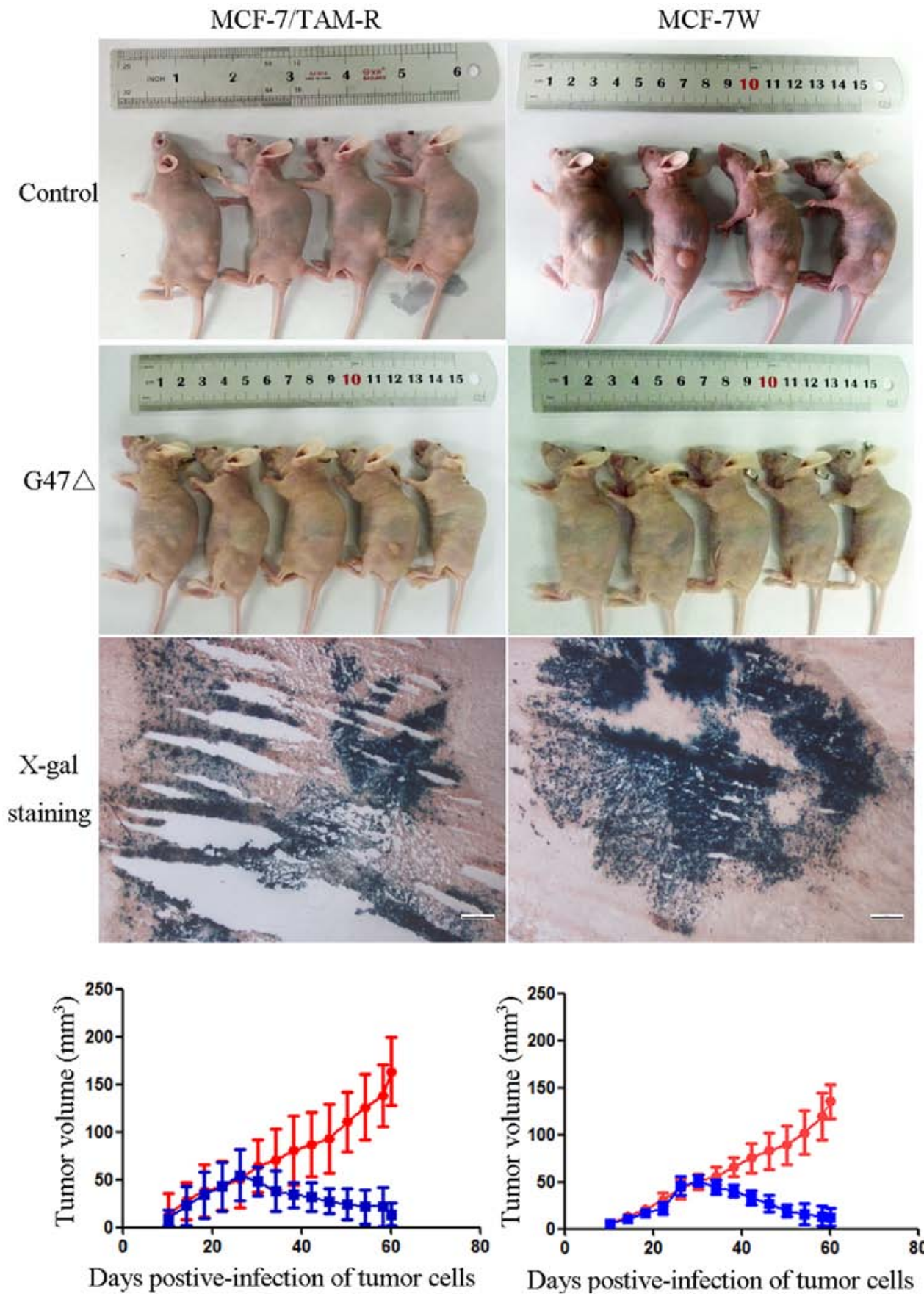

Figure 7. Gross specimens and X-gal staining (magnification, $\mathrm{x} 40$ ) of implanted tumors. G47 $\Delta$ significantly inhibited the tumor growth in both MCF-7/TAM-R and MCF-7W models.

breast cancer cells. The results indicated that G47 $\Delta$ effectively targeted tamoxifen-resistant cells as well as wild-type MCF-7 cells. We further confirmed that when G47D was injected inside the tumor, it not only induced a significant slowdown in tumor growth but also prolonged the survival of both MCF-7/ TAM-R and MCF-7W subcutaneous models.

Traditionally, tamoxifen is the most frequently used medication in endocrine therapy, since it effectively inhibits tumor growth and improves the survival rate of ER-positive patients. Nonetheless, the intrinsic or acquired therapeutic resistance towards tamoxifen limits its long-term application in breast cancer treatment. In the past decades, several scientists have tried to employ a virus vector in breast cancer treatment. G47 $\Delta$, a third generation $\mathrm{HSV}$ vector generated from G207, lacks both copies of neurovirulence $\gamma 34.5$ gene and is inserted in an E. coli LacZ gene into UL39 when compared to wild-type HSV to inactive the ICP6 gene (22). The $\gamma 34.5$ gene is the major determinant of neurovirulence in HSV, and it also significantly enhances the replication ability of HSV-1. Furthermore, the HSV-1 ICP6 gene encodes ribonucleotide reductase and it can reduce ribonucleic acid to deoxyribonucleic, which is associated with DNA damage repair and cell division (23). The deletion of $\gamma 34.5$ and the inactivation of ICP6 ensure that the vector selectively replicates 
in tumor cells but does not introduce any neurotoxicity in normal cells. Moreover, the non-essential ICP47, which inhibits antigen presentation, is deleted in G47 $\Delta$. This enhances MHC class I presentation, increases stimulation of lymphocytes, and decreases NK cytolysis. The promoter region of US11 that inhibits protein synthesis was also nulled, so as to increase virus replication and efficacy (19). In our previous research, G47D was found to be effective and safe in treating various tumors, including nasopharyngeal $(20,22,24-28)$, thyroid (27) and hepatocellular carcinoma (29), breast $(20,22,24-26,30)$ and prostate cancer $(31)$, and malignant glioma $(32,33)$. However, no previous study has confirmed that G47D can effectively target tamoxifen-resistant breast cancer.

Our data confirmed that tamoxifen arrested the cell cycle in the G0/G1 phase and reduced the proportion of MCF-7W cells in the $\mathrm{S}$ phase (34). However, it did not control the cell cycle distribution in the MCF-7/TAM-R cell line. MCF-7 cells are null for the CASP3 gene, therefore the apoptosis requires sequential activation of caspase-9, caspase-7 and caspase-6 (21). BIK is a pro-apoptotic factor of the Bcl-2 protein family and previous research has demonstrated that BIK inhibited Bcl-2 and Bcl-X factor mediating cell proliferation in MCF-7 cells (35). In our study, the expression of caspase-7 and BIK in the MCF-7/TAM-R cells did not change after 4-OHT intervention, confirming that the MCF-7/TAM-R cells were resistant to tamoxifen and were not sensitive to the negative regulatory effects mediated by tamoxifen.

Tamoxifen inhibits breast cancer cell growth by blocking ER; therefore, the expression of ER- $\alpha$ is an important predictor in hormonal therapy. In ER- $\alpha$-positive breast cancer cells, the expression of ER- $\beta$ can increase the sensitivity towards tamoxifen as it downregulates HER2/HER3 signaling and increases the expression of PTEN (36). However, various other research studies have indicated that higher levels of ER- $\beta$ indicate tamoxifen sensitivity $(35,37)$. In cases showing acquired resistance towards tamoxifen, ER- $\alpha$ and ER- $\beta$ exhibit altered structure and function (38). Our results indicated that MCF-7/TAM-R cells had decreased expression of ER- $\alpha$ and ER- $\beta$, demonstrating that the tamoxifen-resistant monoclonal subline was successfully established.

In order to evaluate the impact of G47D on tamoxifenresistant cells, MCF-7/TAM-R and MCF-7W cells were infected with $\mathrm{G} 47 \Delta$ at various MOIs (0.01, 0.1 and 1$)$. In both the MCF-7/TAM-R and MCF-7W cell lines, we observed extremely strong cytotoxic effects even at a very low MOI (0.01). Similarly, G47ه significantly influenced cell cycle distribution, inducing cell cycle arrest at the $\mathrm{G} 2 / \mathrm{M}$ phase in both the MCF-7W and MCF-7/TAM-R cells. Apoptosis analysis also confirmed that G47 $\Delta$ introduced cell apoptosis in the MCF-7W and MCF-7/TAM-R cells. The above results indicate that $\mathrm{G} 47 \Delta$ has great potential in reducing the replication and division of cancer cells. To further verify the antitumor effect of G47 $\Delta$ on tamoxifen-resistant breast cancer in vivo, we employed MCF-7/TAM-R and MCF-7W subcutaneous mouse models in the present study. An intra-tumor G47 $\Delta$ injection significantly reduced tumor growth in both models. In addition, no mouse mortality occurred in the virus-treated group at the end of the study.

There are several limitations to our study. MCF-7 cells alone may not represent all the characteristics of ER-positive breast cancer cells. Additional ER-positive cell lines should be included in future studies. Furthermore, the underlying mechanism involved in the effective inhibition of MCF-7/TAM-R cell growth by G47 $\Delta$ remains undetermined.

In conclusion, G47 $\Delta$, a third generation oHSV, is highly sensitive and safe for targeting tamoxifen-resistant breast cancer cells both in vitro and in vivo.

\section{Acknowledgements}

The present study was supported by the National Natural Science Foundation of China (grant nos. 81172523 and 81372815; principle investigator, R.B.L.).

\section{References}

1. Ferlay J, Soerjomataram I, Dikshit R, Eser S, Mathers C, Rebelo M, Parkin DM, Forman D and Bray F: Cancer incidence and mortality worldwide: Sources, methods and major patterns in GLOBOCAN 2012. Int J Cancer 136: E359-E386, 2015.

2. Pritchard KI, Gelmon KA, Rayson D, Provencher L, Webster M, McLeod D and Verma S: Endocrine therapy for postmenopausal women with hormone receptor-positive her2-negative advanced breast cancer after progression or recurrence on nonsteroidal aromatase inhibitor therapy: A Canadian consensus statement. Curr Oncol 20: 48-61, 2013.

3. Cuzick J, Sestak I, Bonanni B, Costantino JP, Cummings S, DeCensi A, Dowsett M, Forbes JF, Ford L, LaCroix AZ, et al; SERM Chemoprevention of Breast Cancer Overview Group: Selective oestrogen receptor modulators in prevention of breast cancer: An updated meta-analysis of individual participant data. Lancet 381: 1827-1834, 2013.

4. Howell A and Evans DG: Breast cancer prevention: SERMs come of age. Lancet 381: 1795-1797, 2013.

5. Vogel VG: Ongoing data from the breast cancer prevention trials: Opportunity for breast cancer risk reduction. BMC Med 13: 63, 2015.

6. Joy AA, Ghosh M, Fernandes R and Clemons MJ: Systemic treatment approaches in her2-negative advanced breast cancerguidance on the guidelines. Curr Oncol 22 (Suppl 1): S29-S42, 2015.

7. Jordan VC: Chemoprevention of breast cancer with selective oestrogen-receptor modulators. Nat Rev Cancer 7: 46-53, 2007.

8. Freedman OC, Fletcher GG, Gandhi S, Mates M, Dent SF, Trudeau ME and Eisen A: Adjuvant endocrine therapy for early breast cancer: A systematic review of the evidence for the 2014 Cancer Care Ontario systemic therapy guideline. Curr Oncol 22 (Suppl 1): S95-S113, 2015.

9. Pan K and Chlebowski RT: Adjuvant endocrine therapy of perimenopausal and recently postmenopausal women with hormone receptor-positive breast cancer. Clin Breast Cancer 14: 147-153, 2014.

10. Peng J, Sengupta S and Jordan VC: Potential of selective estrogen receptor modulators as treatments and preventives of breast cancer. Anticancer Agents Med Chem 9: 481-499, 2009.

11. Early Breast Cancer Trialists' Collaborative Group (EBCTCG): Effects of chemotherapy and hormonal therapy for early breast cancer on recurrence and 15-year survival: An overview of the randomised trials. Lancet 365: 1687-1717, 2005.

12. Nass N and Kalinski T: Tamoxifen resistance: From cell culture experiments towards novel biomarkers. Pathol Res Pract 211: 189-197, 2015.

13. Eastell R, Adams JE, Coleman RE, Howell A, Hannon RA, Cuzick J, Mackey JR, Beckmann MW and Clack G: Effect of anastrozole on bone mineral density: 5-year results from the anastrozole, tamoxifen, alone or in combination trial $18233230 . \mathrm{J}$ Clin Oncol 26: 1051-1057, 2008.

14. Cuzick J, Sestak I, Forbes JF, Dowsett M, Knox J, Cawthorn S, Saunders C, Roche N, Mansel RE, von Minckwitz G, et al; IBIS-II investigators: Anastrozole for prevention of breast cancer in high-risk postmenopausal women (IBIS-II): An international, double-blind, randomised placebo-controlled trial. Lancet 383: 1041-1048, 2014.

15. Aghi M and Martuza RL: Oncolytic viral therapies - the clinical experience. Oncogene 24: 7802-7816, 2005. 
16. Kaufman HL, Kim DW, DeRaffele G, Mitcham J, Coffin RS and Kim-Schulze S: Local and distant immunity induced by intralesional vaccination with an oncolytic herpes virus encoding GM-CSF in patients with stage IIIc and IV melanoma. Ann Surg Oncol 17: 718-730, 2010.

17. Nakao A, Kasuya H, Sahin TT, Nomura N, Kanzaki A, Misawa M, Shirota T, Yamada S, Fujii T, Sugimoto H, et al: A phase I dose-escalation clinical trial of intraoperative direct intratumoral injection of HF10 oncolytic virus in non-resectable patients with advanced pancreatic cancer. Cancer Gene Ther 18: $167-175,2011$.

18. Geevarghese SK, Geller DA, de Haan HA, Hörer M, Knoll AE Mescheder A, Nemunaitis J, Reid TR, Sze DY, Tanabe KK, et al Phase I/II study of oncolytic herpes simplex virus NV1020 in patients with extensively pretreated refractory colorectal cancer metastatic to the liver. Hum Gene Ther 21: 1119-1128, 2010.

19. Todo T, Martuza RL, Rabkin SD and Johnson PA: Oncolytic herpes simplex virus vector with enhanced MHC class I presentation and tumor cell killing. Proc Natl Acad Sci USA 98: 6396-6401, 2001.

20. Wang J, Hu P, Zeng M, Rabkin SD and Liu R: Oncolytic herpes simplex virus treatment of metastatic breast cancer. Int $\mathrm{J}$ Oncol 40: 757-763, 2012.

21. Coser KR, Wittner BS, Rosenthal NF, Collins SC, Melas A, Smith SL, Mahoney CJ, Shioda K, Isselbacher KJ, Ramaswamy S, et al: Antiestrogen-resistant subclones of MCF-7 human breast cancer cells are derived from a common monoclonal drugresistant progenitor. Proc Natl Acad Sci USA 106: 14536-14541, 2009.

22. Liu R, Varghese S and Rabkin SD: Oncolytic herpes simplex virus vector therapy of breast cancer in C3 (1)/SV40 T-antigen transgenic mice. Cancer Res 65: 1532-1540, 2005.

23. Kanai R, Zaupa C, Sgubin D, Antoszczyk SJ, Martuza RL, Wakimoto $\mathrm{H}$ and Rabkin SD: Effect of $\gamma 34.5$ deletions on oncolytic herpes simplex virus activity in brain tumors. J Virol 86: 4420-4431, 2012.

24. Liu RB and Rabkin SD: Oncolytic herpes simplex virus vectors for the treatment of human breast cancer. Chin Med J 118: 307-312, 2005.

25. Liu R, Martuza RL and Rabkin SD: Intracarotid delivery of oncolytic HSV vector G47delta to metastatic breast cancer in the brain. Gene Ther 12: 647-654, 2005.

26. Zeng W, Hu P, Wu J, Wang J, Li J, Lei L and Liu R: The oncolytic herpes simplex virus vector G47 $\Delta$ effectively targets breast cancer stem cells. Oncol Rep 29: 1108-1114, 2013.
27. Wang JN, Xu LH, Zeng WG, Hu P, Rabkin SD and Liu RR: Treatment of human thyroid carcinoma cells with the g47delta oncolytic herpes simplex virus. Asian Pac J Cancer Prev 16: 1241-1245, 2015.

28. Wang JN, Hu P, Zeng MS and Liu RB: Anti-tumor effect of oncolytic herpes simplex virus G47delta on human nasopharyngeal carcinoma. Chin J Cancer 30: 831-841, 2011.

29. Wang J, Xu L, Zeng W, Hu P, Zeng M, Rabkin SD and Liu R: Treatment of human hepatocellular carcinoma by the oncolytic herpes simplex virus G47delta. Cancer Cell Int 14: 83, 2014.

30. Zeng WG, Li JJ, Hu P, Lei L, Wang JN and Liu RB: An oncolytic herpes simplex virus vector, G47 $\Delta$, synergizes with paclitaxel in the treatment of breast cancer. Oncol Rep 29: 2355-2361, 2013.

31. Passer BJ, Wu CL, Wu S, Rabkin SD and Martuza RL: Analysis of genetically engineered oncolytic herpes simplex viruses in human prostate cancer organotypic cultures. Gene Ther 16 1477-1482, 2009

32. Sgubin D, Wakimoto H, Kanai R, Rabkin SD and Martuza RL: Oncolytic herpes simplex virus counteracts the hypoxia-induced modulation of glioblastoma stem-like cells. Stem Cells Trans Med 1: 322-332, 2012

33. Barnard Z, Wakimoto H,Zaupa C,Patel AP, Klehm J, Martuza RL, Rabkin SD and Curry WT Jr: Expression of FMS-like tyrosine kinase 3 ligand by oncolytic herpes simplex virus type I prolongs survival in mice bearing established syngeneic intracranial malignant glioma. Neurosurgery 71: 741-748, 2012.

34. Ichikawa A, Ando J and Suda K: G1 arrest and expression of cyclin-dependent kinase inhibitors in tamoxifen-treated MCF-7 human breast cancer cells. Hum Cell 21: 28-37, 2008.

35. Hodges-Gallagher L, Valentine CD, El Bader S and Kushner PJ: Estrogen receptor beta increases the efficacy of antiestrogens by effects on apoptosis and cell cycling in breast cancer cells. Breast Cancer Res Treat 109: 241-250, 2008.

36. Lindberg K, Helguero LA, Omoto Y, Gustafsson JA and Haldosén LA: Estrogen receptor $\beta$ represses Akt signaling in breast cancer cells via downregulation of HER 2/HER3 and upregulation of PTEN: Implications for tamoxifen sensitivity. Breast Cancer Res 13: R43, 2011.

37. Haldosén LA, Zhao C and Dahlman-Wright K: Estrogen receptor beta in breast cancer. Mol Cell Endocrinol 382: 665-672, 2014.

38. Huang B, Warner M and Gustafsson JÅ: Estrogen receptors in breast carcinogenesis and endocrine therapy. Mol Cell Endocrinol: Nov 26, 2014 (Epub ahead of print). pii: S03037207(14)00371-2. doi: 10.1016/j.mce.2014.11.015. 